\title{
IJO-SCIENCE
}

INTERNATIONAL JOURNAL ONLINE OF SCIENCE

ISSN: 2455-0108

\section{ANALYSIS OF FATIGUE OF CONNECTING ROD ZL 109 BY USING FINITE ELEMENT METHOD}

\author{
Amita Saxena ${ }^{1}$, Ashish Kumar Sinha ${ }^{2}$ \\ PG Scholar ${ }^{1}$, Assistant Professor ${ }^{2}$
}

Department of Mechanical Engineering, Oriental Institute of Science \& Technology, Bhopal

\begin{abstract}
The connecting rod is the intermediate member between the piston and the Crankshaft. Its primary function is to transmit the push and pull from the piston pin to the crank pin, thus converting the reciprocating motion of the piston into rotary motion of the crank. Existing connecting rod is manufactured by using Carbon steel. The axial stresses are produced due to cylinder gas pressure (compressive only) and the inertia force arising in account of reciprocating action (both tensile as well as compressive), where as bending stresses are caused due to the centrifugal effects. The result of which is, the maximum stresses are developed at the fillet section of the big and the small end. Hence, the project deals with the stress analysis of connecting rod by Finite Element Method ANSYS WORKBENCH 16.0 Software. The main objective in this paper to review on design evaluation and optimization of connecting rod parameters by using finite element method is to achieve suitable design for connecting rod. That can be achieved by changing such design parameters in the existing design. Finite element analysis of single cylinder four stroke petrol engines is taken for the study; Structural systems of Connecting rod can be easily analyzed using Finite Element techniques. So firstly a proper Finite Element Model is developed using CAD software. Then static and dynamic analysis is done to determine the von Misses stress, shear stress, elastic strain, total deformation in the present design connecting rod for the given loading conditions using Finite Element Analysis Software ANSYS v 16.In the first part of the study, the static and dynamic loads acting on the connecting rod, After that the work is carried out for safe design. Based on the observations of the static FEA and the load analysis results, the load for the optimization study was selected. The results were also used to determine of various stress and the fatigue model to be used for analyzing the fatigue strength. Outputs of the fatigue analysis of include fatigue life, damage, factor of safety, stress biaxiality indication. Then results of present model in ANSYS 16.0 are compared with the results of existing design in the reference paper.
\end{abstract}

Keywords: ANSYS, FEA, Connecting Rod, Fatigue life, Factor of safety

\section{INTRODUCTION}

The intermediate component between crank and piston is known as connecting rod. The objective of C.R. is to transmit push \& pull from the piston pin to the crank pin and then converts reciprocating motion of the piston into the rotary motion of crank. The components are big shank, a small end and a big end. The cross section of shank may be rectangular, circular, tubular, ISection, + -section or ellipsoidal-Section. It sustains force generated by mass \& fuel combustion. The resulting bending stresses appear due to eccentricities, crank shaft, case wall deformation \& rotational mass. FEA approach deals with structural analysis along with various parameters which affects its working \& define best solution to overcome the barriers associated with it. The structural analysis allows stresses \& strains to be calculated in FEA, by using the structural model. The structural analysis performed to create high \& low stresses region from the input of the material, loads, boundary condition. FEA approach was adopted in structural analysis to overcome the barriers associated with the geometry \& boundary condition. It is used to improve optimize design. The main objective of this work is to determine shear stresses and optimization in the existing connecting rod, which are in different crosssection as plus (+) section, I-section and ellipsoidal section. The failures of existing design suggest the minimum design changes in the existing connecting rod. 


\section{IJO-SCIENCE}

\section{INTERNATIONAL JOURNAL ONLINE OF SCIENCE}

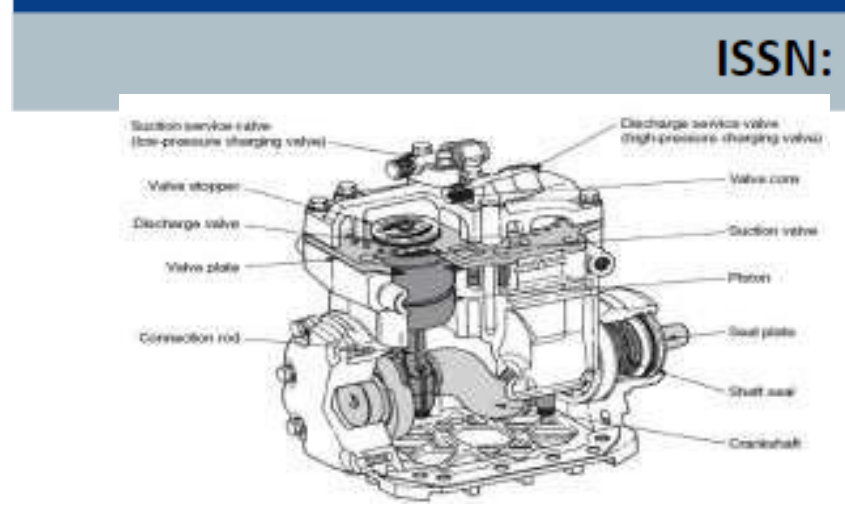

Figure 1: Overview of engine parts

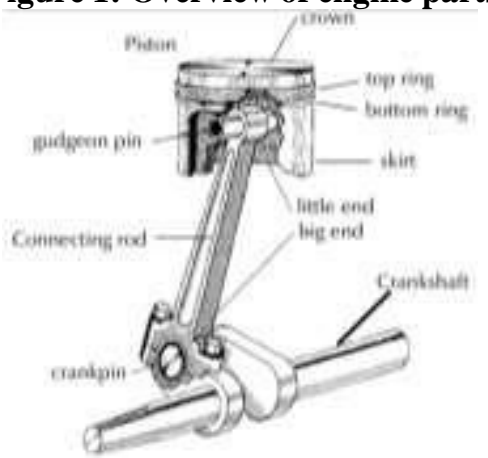

Figure 2: Connecting Rod assembly

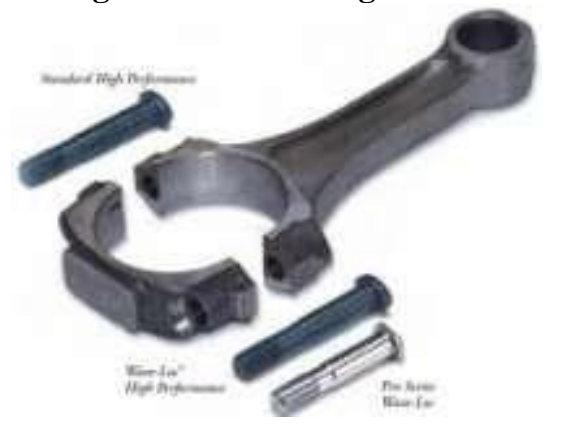

Figure 3: Connecting Rod's parts

\subsection{Small end and big end:}

The small end attaches to the piston pin, gudgeon pin or wrist pin, which is currently most often press fit into the connecting rod but can swivel in the piston, a "floating wrist pin" design. The big end connects to the bearing journal on the crank throw, in most engines running on replaceable bearing shells accessible via the connecting rod bolts which hold the bearing "cap" onto the big end. Typically there is a pinhole bored through the bearing and the big end of the connecting rod so that pressurized lubricating motor oil squirts out onto the thrust side of the cylinder wall to lubricate the travel of the pistons and piston rings. Most small two-stroke engines and some single cylinder four-stroke engines avoid the need for a pumped lubrication system by using a rolling-element bearing instead, however this requires the crankshaft to be pressed apart and then back together in order to replace a connecting rod.

\subsection{Engine wear and rod length:}

A major source of engine wear is the sideways force exerted on the piston through the connecting rod by the crankshaft, which typically wears the cylinder into an oval cross section rather than circular, making it impossible for piston rings to correctly seal against the cylinder walls. Geometrically, it can be seen that longer connecting rods will reduce the amount of this sideways force, and therefore lead to longer engine life. However, for a given engine block, the sum of the length of the connecting rod plus the piston stroke is a fixed number, determined by the fixed distance between the crankshaft axis and the top of the cylinder block where the cylinder head fastens; thus, for a given cylinder block longer stroke, giving greater engine displacement and power, requires a shorter connecting rod (or a piston with smaller compression height), resulting in accelerated cylinder wear.

\subsection{Stress failures:}

The connecting rod is under tremendous stress from the reciprocating load represented by the piston, actually stretching and being compressed with every rotation, and the load increases to the square of the engine speed increase. Failure of a connecting rod, usually called throwing a rod is one of the most common causes of catastrophic engine failure in cars, frequently putting the broken rod through the side of the crankcase and thereby rendering the engine irreparable; it can result from fatigue near a physical defect in the rod, lubrication failure in a bearing due to faulty maintenance, or from failure of the rod bolts from a defect, improper tightening or over- revving of the engine. Re-use of rod bolts is a common practice as long as the bolts meet manufacturer specifications. Despite their frequent occurrence on televised competitive automobile events, such failures are quite rare on production cars during normal daily driving. This is because production auto parts have a much larger factor of safety, and often more systematic quality control.

\section{LITERATURE REVIEW}

The following research papers are consulted for obtaining an in-depth understanding of various aspects of the project:-

\section{BASED ON MATERIAL USED:-}

\subsubsection{ALUMINUM}

G. Naga Malleshwara Rao et al. [2] explore weight reduction opportunities in the connecting rod of an I.C. engine by examining various materials such as Genetic Steel, Aluminum, Titanium and Cast Iron. This was entailed by performing a detailed load analysis. Therefore, this study has dealt with two subjects, first, static load and stress analysis of the connecting rod and second, Design Optimization for suitable material to minimize the deflection. 
K. Sudershn Kumar et al. [3] describes modelling and analysis of connecting rod. In this project connecting rod is replaced by Aluminum reinforced with Boron carbide for Suzuki GS150R motorbike. A 2D drawing is drafted from the calculations. A parametric model of connecting rod is modeled using PRO-E 4.0 software. Analysis is carried out by using ANSYS software.

K. Sudershn Kumar et al. [14], for considering the parameters, the working factor of safety is nearer to theoretical factor of safety in aluminum boron carbide. Percentage of reduction in weight is same in Aluminum 360 and aluminum boron carbide. Percentage of increase in stiffness in aluminum boron carbide is more. Percentage of reducing in stress ALUMINIUM BORON CARBIDE and ALUMNUM is same than CARBON STEEL.

Priyank D. Toliya, Ravi C. Trivedi, Prof. Nikhil J. Chotai et al. [17], investigate the failure analysis of the connecting rod of the automotive engine. Apart from conventional material of connecting rod I choose the connecting rod of FM-70 Diesel engine which is made of Aluminum 6351. static analysis is done to determine the von Misses stress, elastic strain, total deformation in the present design connecting rod for the given loading conditions using the FEM Software ANSYS 12.1 .In the starting of the work, the static loads acting on the connecting rod, After that the work is carried out for safe design and life in fatigue. Fatigue Analysis is compared with the Experimental results.

\subsubsection{STEEL}

P S. Shenoy et al.[7] carried out the dynamic load analysis and optimization of connecting rod. The main objective of this study was to explore weight and cost reduction opportunities for a production forged steel connecting rod. Typically, an optimum solution is the minimum or maximum possible value the objective function could achieve under a defined set of constraints. The weight of the connecting rod has little influence on the cost of the final component. Change in the material, resulting in a significant reduction in machining cost, was the key factor in cost reduction. As a result, in this optimization problem the cost and the weight were dealt with separately. The structural factors considered for weight reduction during the optimization include the buckling load factor, stresses under the loads, bending stiffness, and axial stiffness. Cost reduction is achieved by using C-70 steel, which is fracture crack able. It eliminates sawing and machining of the rod and cap mating faces and is believed to reduce the production cost by $25 \%$.

Abhinav Gautam, K Priya Ajit et al. [9] describes static stress analysis of connecting rod made up of SS 304 used in Cummins NTA 885 BC engine is conducted, It is observed that the area close to root of the smaller end is very prone to failure, may be due to higher crushing load due to gudgeon pin assembly. As the stress value is maximum in this area and stresses are repetitive in nature so chances of fatigue failure are always higher close to this region.

T S. Sarkate et al. [20] concluded that the stress analysis of connecting used in engine has been presented and discuss in this paper. The results obtain by FEA for both Aluminum 7068 alloy and AISI 4340 alloy steel are satisfactory for all possible loading conditions. By using Aluminum 7068 alloy instead of AISI 4340 alloy steel can reduce weight up to $63.95 \%$. Also equivalent stresses for Aluminum 7068 alloy is less by $3.59 \%$. The factor of safety of connecting rod will reduce by $9.77 \%$ in case tensile load applied at crank end but it will increase in all other load conditions if Aluminum7068 alloy is used instead of AISI 4340

\subsubsection{COMPOSITE MATERIAL}

M. Faheem et al. [11] concluded that Weight can be reduced by changing the material of the current al360 connecting rod to hybrid ALFASiC composites. The new optimized connecting rod is comparatively much stiffer than the former.

\section{BASED ON MODELING SOFTWARE ANSYS}

S Pal et al. [1] describes FEA of single cylinder four stroke petrol engines is taken for the study; Structural systems of Connecting rod can be easily analyzed using Finite Element techniques. So firstly a proper Finite Element Model is developed using CAD software. Then static analysis is done to determine the von Misses stress, shear stress, elastic strain, total deformation in the present design connecting rod for the given loading conditions using Finite Element Analysis Software ANSYS v 12.In the first part of the study, the static loads acting on the connecting rod, After that the work is carried out for safe design.

V. B Reddy et al. [5] modelled connecting rod imported to the analysis software i.e. ANSYS. Static analysis is done to determine von-misses stresses, strain, shear stress and total deformation for the given loading conditions using analysis software i.e. ANSYS. In this analysis two materials are selected and analyzed. The software results of two materials are compared and utilized for designing the connecting rod.

H. B. Ramani et al. [6] detailed load analysis was performed on connecting rod, followed by finite element method in ANSYS-13 medium. In this regard, In order to calculate stress in Different part of connecting rod, the total forces exerted connecting rod were calculated and then it was modelled, meshed and loaded in ANSYS software. The maximum stresses in different parts of connecting rod were determined by Analysis. The maximum pressure stress was between pin end and rod linkages and between bearing cup and connecting rod linkage. The maximum tensile stress was obtained in lower half of pin end and between pin end and rod linkage. It is suggested that the results obtained can be useful to bring about modification in Design of connecting 
rod.

S kumar et al. [15], describes Finite Element analysis of the connecting rod of a Hero Honda Splendor has been done using FEA tool ANSYS Workbench. It is concluded that the weight of the connecting rod is also reduced by $0.477 \mathrm{~g}$. Thereby, reduces the inertia force. Fatigue strength is the most important driving factor for the design of connecting rod and it is found that the fatigue results are in good agreement with the existing result.

Pro/E

B. Anusha et al. [4] describes static analysis is conducted on a connecting rod of a single cylinder 4-stroke petrol engine. The model is developed using Solid modelling software i.e. PRO/E (creo-parametric). Further finite element analysis is done to determine the von-misses stresses shear stress and strains for the given loading conditions.

K.M Bhuptani et al. [19] observed the intermediate member between piston and the Crankshaft. Its primary function is to transmit the push and pull from the piston pin to the crank pin, thus converting the reciprocating motion of the piston into rotary motion of the crank. Existing Bearing of connecting rod is manufactured by using nonferrous materials like Gunmetal, Phosphor Bronze etc. This paper describes modeling and analysis of connecting rod bearing for small end using ProE Wildfire 4.0.A two dimensional drawing is drafted from the calculations. A parametric model of bearing is modeled using PRO-E 4.0 software. Analysis is carried out by using Pro-mechanica software. Static structural analysis of Bearing for small end of connecting rod is done by considering three different materials. The best combination of parameters like Von misses stress; Maximum shear stress and weight reduction for Four stroke diesel engine were studied in ProE software.

\section{NUMERICAL ANALYSIS}

P S. Shenoy et al. [12] Optimization was performed to reduce weight and manufacturing cost of a forged steel connecting rod subjected to cyclic load comprising the peak compressive gas load and the peak dynamic tensile load at $5700 \mathrm{rev} / \mathrm{min}$, corresponding to 360o crank angle. B. Anusha, Dr.C. Y. Kumari, Dr. B V R Gupta et al. [8] Carried out the Dynamic Analysis \& Optimization of Connecting Rod Using FEM, The main objective of this study was to explore weight and cost Reduction opportunities for a production forged steel connecting rod. This study has dealt with two subjects, first, dynamic load of the connecting rod, and second, optimization for weight and cost. In the first part, the relations for obtaining the loads and accelerations for the connecting rod at a given constant speed of the crankshaft were also determined. Quasi dynamic finite element analysis was performed at several crank angles. After that the component was optimized for weight and cost subject, and space constraints and manufacturability. While performing quasi-dynamic FEA of the connecting rod as shown in figure, external loads computed from the load analysis were applied to both the crank end and the piston pin end of the connecting rod. Many FE models were solved, each model with the applied loads obtained from the load analysis at the crank angle of interest. Therefore, such analysis is different from a static analysis as the timevarying dynamic nature of the loading represented by load variation at different crank angles is accounted for. It should also be noted that the dynamic load analysis step was required as a separate step, as input to the stress analysis step using IDEAS

$\mathbf{R}$ Bansal et al.[10] noted that the connecting rod deformation was mainly bending due to buckling under the critical loading. And the maximum deformation was located due to crush \& shear failure of the big \& small end bearings. So these areas prone to appear the fatigue crack. Base on the results, we can forecast the possibility of mutual interference between the connecting rod and other parts. The results provide a theoretical basis to optimize the design and fatigue life calculation.

GVSS Sharma et al. [13] describes Statistical process control is an excellent quality assurance tool to improve the quality of manufacture and ultimately scores on endcustomer satisfaction. SPC uses process monitoring charts to record the key quality characteristics (KQCs) of the component in manufacture. This paper elaborates on one such KQC of the manufacturing of a connecting rod of an internal combustion engine.

V C. Pathade et al. [16], concluded that, Finite Element Analysis and Photoelastic Analysis it is found that i) The stresses induced in the small end of the connecting rod are greater than the stresses induced at the big end. ii) Form the photoelastic analysis(from the fringe developed in the photoelastic model of connecting rod) it is found that the stress concentration effect exist at both small end and big end and it is negligible in the middle portion of the connecting rod. iii) Therefore, the chances of failure of the connecting rod may be at fillet section of both ends.

S. Shaari et al. [18] concluded that the modeling of connecting rod and FE Analysis has been presented. Topology optimization were analyzed to the connecting rod and according to the results, it can be concluded that the weight of optimized design is $11.7 \%$ lighter and maximum stress also predicted lower than the initial design of connecting rod. The results clearly indicate that the new design much lighter and has more strength than initial design of connecting rod.

A. Strozzi et al. [21] concluded both typical and uncommon failure modes in con-rods for internal combustion engines have been commented from the stress level viewpoint. The interpretation of the fractures has been supported with traditional calculations, with more advanced analytical models, and with FE predictions. With respect to the con-rod shank, the fatigue cracks 


\section{IJO-SCIENCE}

\section{INTERNATIONAL JOURNAL ONLINE OF SCIENCE}

\section{ISSN: 2455-0108}

occurring at the transition zone between the little finish and therefore the shank are thought-about, and therefore the corresponding stress concentrations are illustrated with a Fe analysis. Samples of facet buckling, of front-rear buckling, and of plastic torsion of the con-rod shank, are bestowed, and their attainable causes are explored. The incidence of an uncommon $45^{\circ}$ crack within the con-rod shank has been even. An uncommon crack, ripping the full con-rod into 2 elements, has been careful, and therefore the tensile stresses promoting such crack are attributed to a non ancient pure mathematics of the eye-shank transition zone. The influence of the I-shaped and formed shank geometries on the pressure peaks at the contact between the wrist pin and therefore the little finish bore has been illustrated with Fe. Moving to the con-rod little finish, each photoelastic and Fe studies are used to proof that the height stress happens at the little finish bore sides. The attainable positions of the lubrication hole are classified. Recent analytical results on the result of the initial clearance between the little finish bore and therefore the pin bound on the little finish stress field are reported.

According to these results, the extent of the contact arc between the little finish and therefore the wrist pin depends on the magnitude relation between the load and therefore the clearance; consequently, this magnitude relation could also be treated as one variable. The validity of this analytical result has experimentally been assessed with a selected photoelastic analysis. The unsought rotation of the bush forced into the little finish, inflicting obstruction of the lubrication hole and seizure, has been thought-about. the result of fretting fatigue cracks has been illustrated, and an output expressed in terms of the Ruiz fretting fatigue parameter has been provided for a selected titanium con-rod; this output justifies the crack initiation at the little finish bore however not at the bores sides, wherever the utmost circumferential stresses occur.

\section{MATERIAL FOR CONNECTING ROD}

The ZL109 materials have been used in present work. Alloying elements in the material enables hardening of forged connecting rod when they undergo controlled cooling after forging. The properties of material are initial input for optimization task thus it play a very important role in optimization task. Connecting rod was design \& modelled by using CAD. It was then imported to ANSYS v 16.0 for analysis.

\subsection{Chemical composition of ZL-109}

Table 1: Chemical Composition of ZL-109

\begin{tabular}{|c|c|}
\hline Name of element & \% of element \\
\hline $\mathrm{Si}$ & $11.0-13.0$ \\
\hline $\mathrm{Cu}$ & $0.5-1.5$ \\
\hline $\mathrm{Mg}$ & $0.8-1.3$ \\
\hline
\end{tabular}

\begin{tabular}{|c|c|}
\hline Mn & --- \\
\hline Ti & ---- \\
\hline
\end{tabular}

Table 2: Mechanical properties of ZL-109

\begin{tabular}{|c|c|c|}
\hline $\begin{array}{c}\text { S. } \\
\text { No. }\end{array}$ & $\begin{array}{c}\text { Mechanical } \\
\text { Properties }\end{array}$ & $\begin{array}{l}\text { C } \\
\text { steel } \\
\text { values }\end{array}$ \\
\hline $\mathbf{1}$ & Density (g/cc) & 7.9 \\
\hline $\mathbf{2}$ & $\begin{array}{c}\text { Modulus of } \\
\text { elasticity (GPa) }\end{array}$ & 225 \\
\hline $\mathbf{3}$ & $\begin{array}{c}\text { Yield Strength, Sy } \\
(\mathrm{MPa})\end{array}$ & 445 \\
\hline $\mathbf{4}$ & $\begin{array}{c}\text { Tensile } \\
\text { Strength,Su } \\
(\mathrm{MPa})\end{array}$ & 675.5 \\
\hline $\mathbf{5}$ & Poison ratio & 0.30 \\
\hline
\end{tabular}

Table 3: Engine Technical Specifications [34]

\begin{tabular}{|l|l|}
\hline Specifications & Dimensions \\
\hline Model & $\begin{array}{l}\text { Royal Enfield Bullet Diesel } \\
\text { Taurus }\end{array}$ \\
\hline Type & Motorcycle \\
\hline $\begin{array}{l}\text { Engine } \\
\text { Displacement }\end{array}$ & $350 \mathrm{cc}$ \\
\hline Engine Starting & Kick \\
\hline Engine Type & 4 stroke \\
\hline Cooling Type & Air Cooled \\
\hline Maximum Power & $6.50 \mathrm{HP}(4.7 \mathrm{KW})$ \\
\hline Maximum Torque & $15 \mathrm{~N}-\mathrm{m} @ 2500 \mathrm{rpm}$ \\
\hline Transmission & Manual 4 Speed \\
\hline Compression Ratio & $22: 1$ \\
\hline $\begin{array}{l}\text { Connecting Rod } \\
\text { Length }\end{array}$ & $180 \mathrm{~mm}$ \\
\hline
\end{tabular}

Table 4: Forged Steel Composition [35]

\begin{tabular}{|l|l|l|l|l|l|l|l|l|}
\hline Material & $\mathbf{C}$ & $\mathbf{N i}$ & $\mathbf{C r}$ & $\mathbf{M n}$ & $\mathbf{P}$ & $\mathbf{S}$ & $\mathbf{S i}$ & $\mathbf{M o}$ \\
\hline \% wt & 0.35 & 3 & $0.80-$ & $0.75-$ & 0.0 & 0.04 & $0.2-$ & $0.15-$ \\
& - & & 1.10 & 1.0 & 35 & 0 & 0.35 & 0.25 \\
& 0.45 & & & & & & & \\
\hline
\end{tabular}

Workers roll out the spray-up to compact the laminate. Wood, foam, or other core material may then be added, and a secondary spray-up layer embeds the core between the laminates. The part is then cured, cooled, and removed from the mold.

\section{CAE TOOLS AND SOFTWARE}

Computer-Aided Engineering (CAE) is the broad usage of computer software to aid in engineering tasks. It includes computer aided design (CAD), computer aided analysis (CAA), computer integrated manufacturing (CIM), computer aided manufacturing (CAM), material requirements planning (MRP) and computer-aided planning (CAP).CAE embraces the application of 


\section{IJO-SCIENCE}

\section{INTERNATIONAL JOURNAL ONLINE OF SCIENCE}

\section{ISSN: 2455-0108}

computers from preliminary design (CAD) through production (CAM). Computer Aided Analysis includes finite element and finite difference method for solving the partial differential equations governing solid mechanics, fluid mechanics and heat transfer, but it also includes diverse program for specialized analyses such as rigid body dynamics and control system modeling. Recently, manufactures have been asked to design their products for eventual recycling, and this aspect of engineering will undoubtedly fall under the umbrella of CAE, but as of yet it doesn't have its own acronym. CAE tools are being used, for example, to analyze the robustness and performance of components and assemblies. The term encompasses simulation, validation, and optimization of products and manufacturing tools. In the future, CAE systems will be major providers of information to help support design teams in decision making. CAE areas covered include:

- Stress analysis on components and assemblies using FEA (Finite Element Analysis);

- Thermal and fluid flow analysis Computational fluid dynamics (CFD);

- Kinematics;

- Mechanical event simulation (MES)

- Analysis tools for process simulation for operations such as casting, molding, and die press forming.

- Optimization of the product or process.

\section{RESULTS \& ANALYSIS}

Both Static and dynamic analysis are done on connecting rod, which is made by ZL-109 Al Alloy. In results shows the temperatures variations, stress variation, von mises stress variation, life variation on the designed connecting rod.

\subsection{STATIC ANALYSIS FOR ZL109}

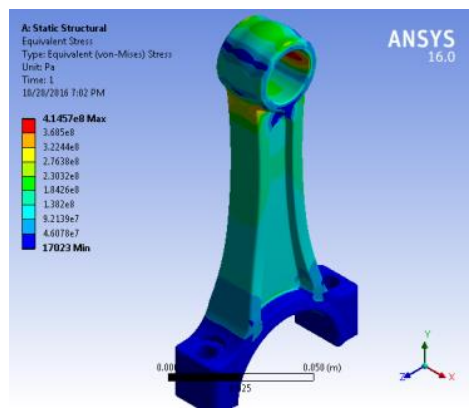

Figure 4: Equivalent Stress analysis static condition

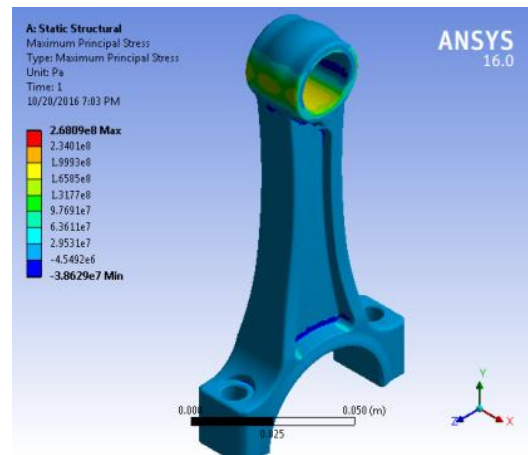

Figure 5: Maximum principal stress variation at static condition

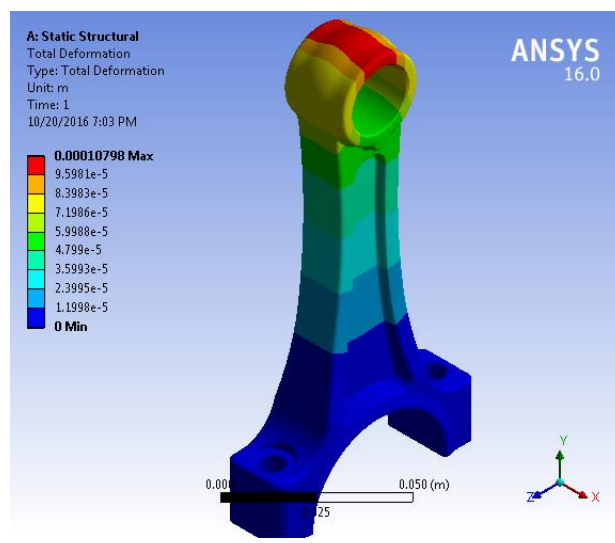

Figure 6: Total deformation variation at staticcondition

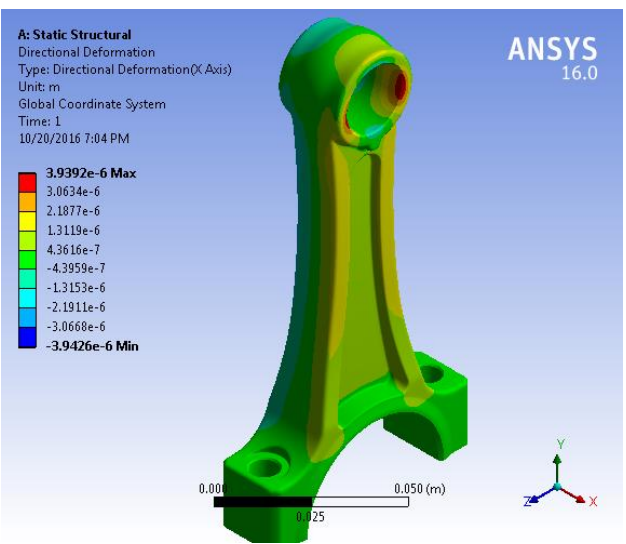




\section{IJO-SCIENCE}

\section{INTERNATIONAL JOURNAL ONLINE OF SCIENCE}

\section{ISSN: 2455-0108}

Figure 7: Directional deformation ( $x$ axis) variation at static condition

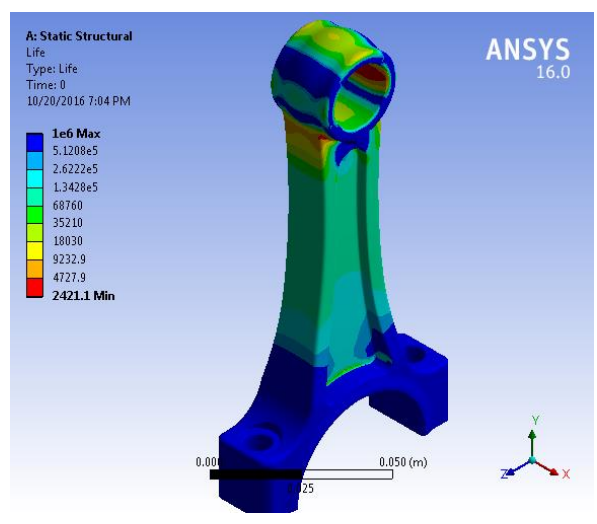

Figure 7: Life variation at static condition

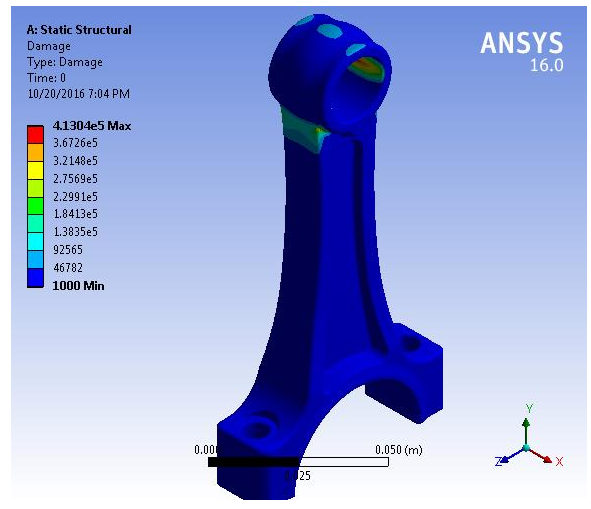

Figure 8: Damage variation at static condition

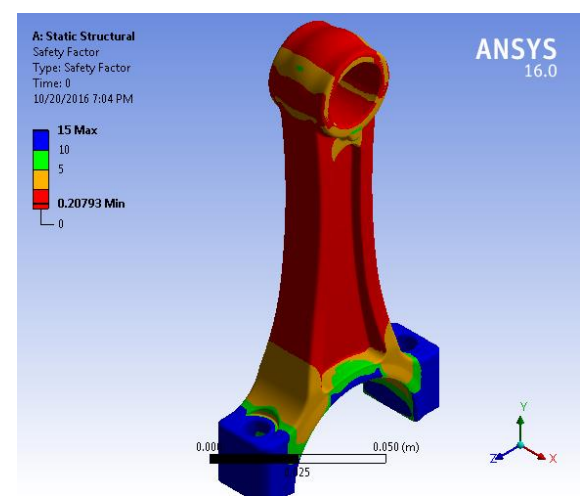

Figure 9: Factor of safety at static condition

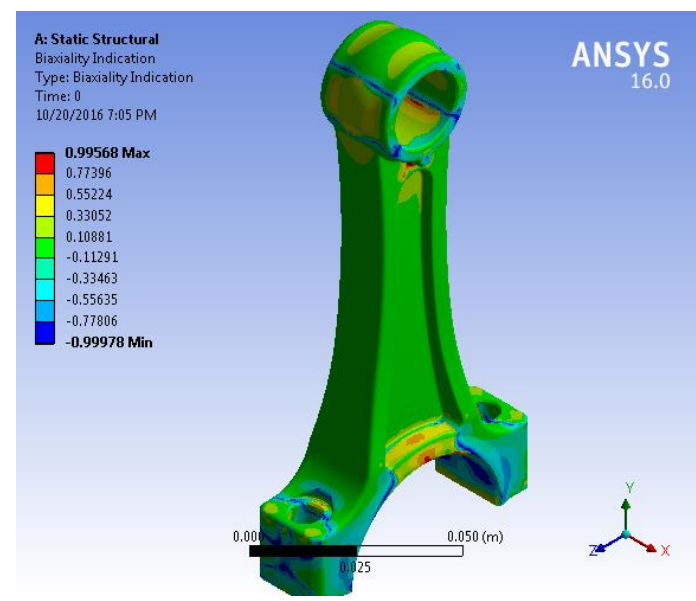

Figure 10: Biaxial Indication at static condition

\subsection{DYNAMIC ANALYSIS FOR ZL109}

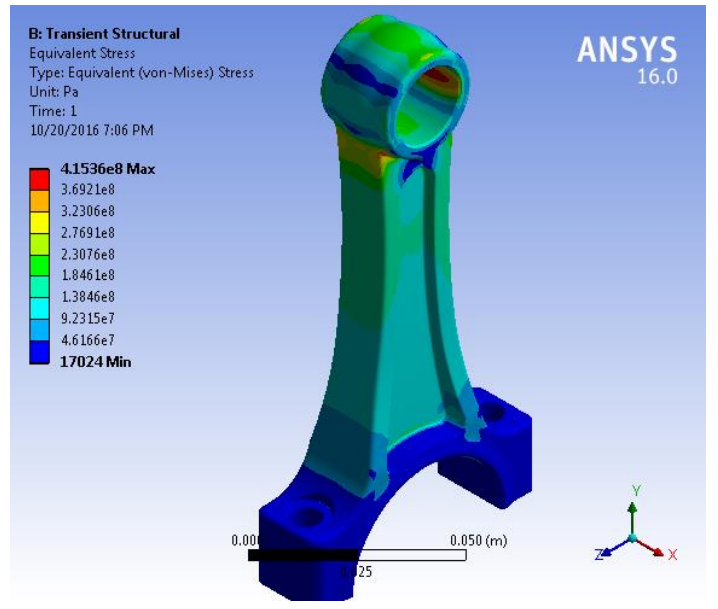

Figure 11: Equivalent stress variation at dynamic condition 


\section{IJO-SCIENCE}

\section{INTERNATIONAL JOURNAL ONLINE OF SCIENCE}

ISSN: 2455-0108

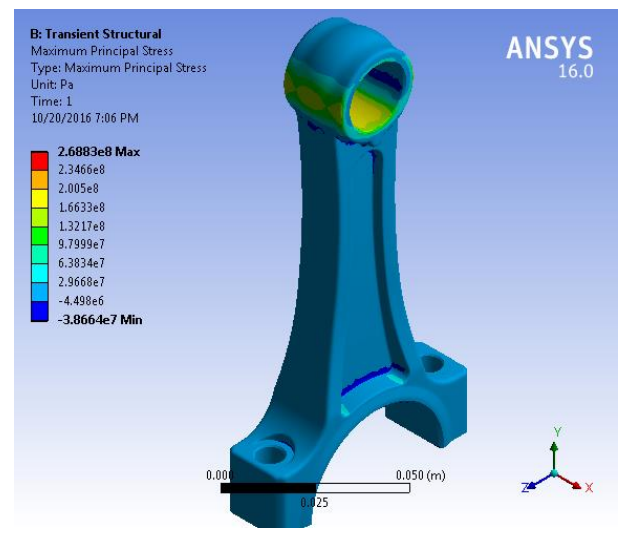

Figure 12: Maximum Principal Stress variation at dynamic condition

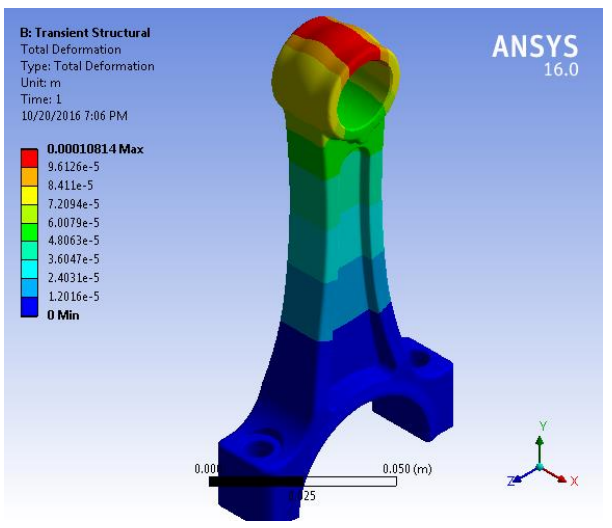

Figure 13: Total Deformation variation at dynamic condition

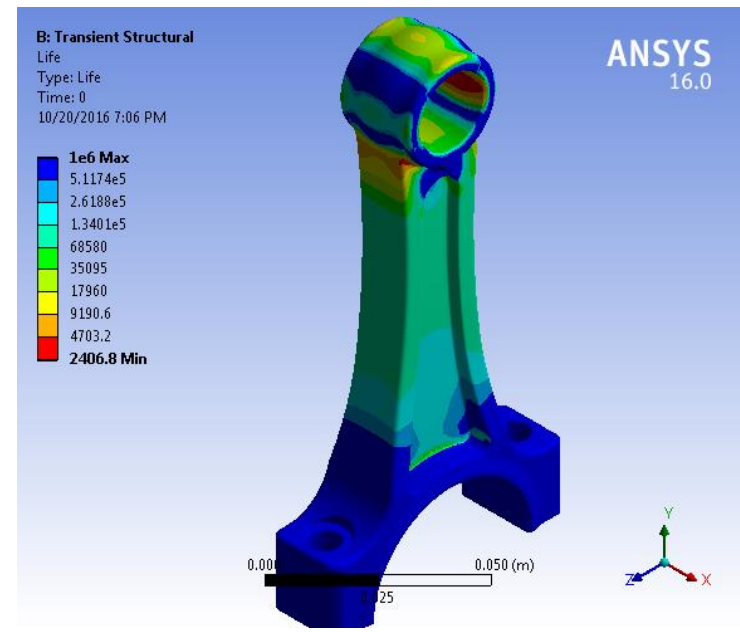

Figure 14: Life variation at dynamic condition

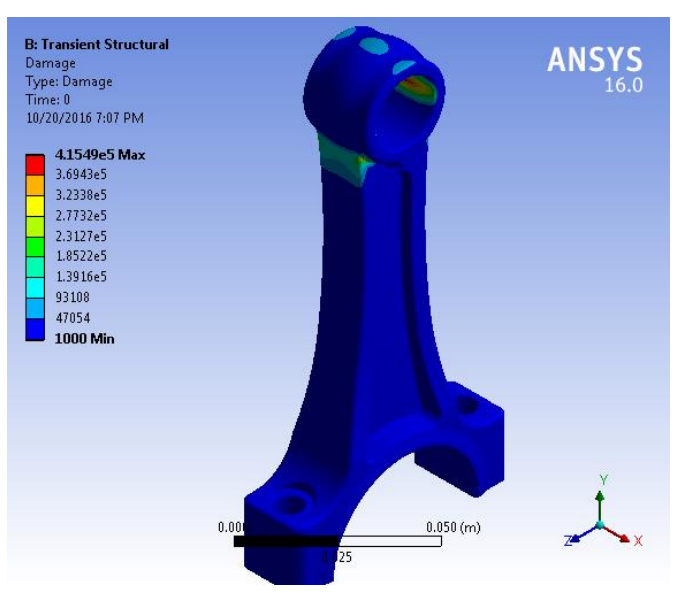

Figure 15: Damage variation at dynamic condition 


\title{
IJO-SCIENCE
}

\section{INTERNATIONAL JOURNAL ONLINE OF SCIENCE}

\author{
ISSN: 2455-0108
}

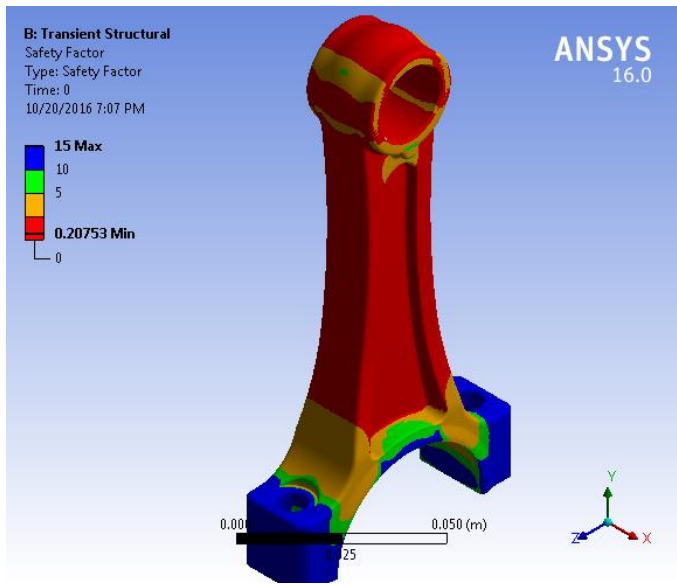

Figure 16: Factor of safety variation at dynamic condition

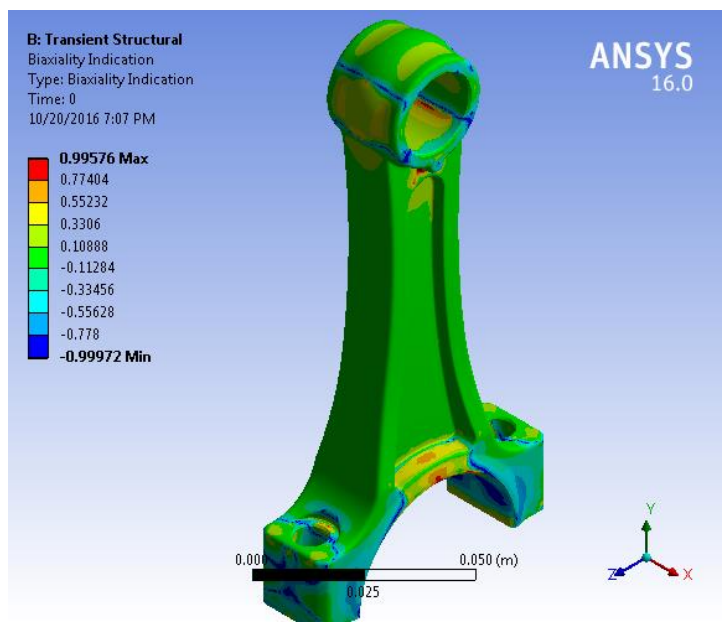

Figure 16: Biaxial indication at dynamic condition

\section{CONCLUSION}

This research work basically focuses on replacing conventional material of connecting rod with new material ZL109 aluminium alloy. Presently the automotive/automobile industries are using forged steel alloy for connecting rod which is more bulky with less material strength. Hence the research work basically focuses on replacing the conventional material with that of the aluminium alloy which reduces the weight of the component without affecting the performance of the connecting rod.

There are following concluding points having been proposed for this work:

- For the static structural analysis the total deformation of connecting rod for conventional material has been obserbed its maximum and minimum values are $0.10799 \mathrm{~mm} \& 0 \mathrm{~mm}$. and the directional deformation has been observed as $0.003939 \mathrm{~mm}$ for maximum and $-0.0039432 \mathrm{~mm}$ for minimum deformation, The maximum and minimum values of Von-mises of equivalent stresses are $414.62 \mathrm{MPa} \& 0.017025 \mathrm{MPa}$ and The maximum principal stress of connecting rod for conventional material has been observed its maximum and minimum values are $268.13 \mathrm{MPa} \&$ 38.635 MPa. The Fatigue Stress Life of the connecting rod is based on S-N curves is 10e6, the maximum value of biaxiality is 0.98792 which is less than one that indicates pure biaxial state. Fatigue Sensitivity Chart Shows how the fatigue results change with loading at the critical location on the components which shows the sensitivity for life of component the maximum available life 35777 cycles with respect to 1.5 loading history.

- For dynamic structural analysis the total deformation of connecting rod for conventional matrial has been obserbed its maximum and minimum values are $0.10799 \mathrm{~mm} \& 0 \mathrm{~mm}$. maximum and minimum values of directional deformation are $0.028499 \mathrm{~mm} \&$ $0.028502 \mathrm{~mm}$. The equivalent stress or von-mises stress of connecting rod for conventional material has been obserbed its maximum and minimum values are $366.54 \mathrm{Mpa} \& 0.039309 \mathrm{Mpa}$ and maximum and minimum values of The maximum principal stresses are 268.13 MPa \& -38.635 MPa, The Fatigue Stress Life of the connecting rod is based on S-N curves is $10 \mathrm{e} 6$ the maximum value of biaxiality is 0.99568 which is less than one that indicates pure biaxial state. Fatigue Sensitivity Chart Shows how the fatigue results change with loading at the critical location on the components which shows the sensitivity for life of component the maximum available life 35777 cycles with respect to 1.5 loading history. For Fatigue Damage values greater than $1 \mathrm{e} 6$ indicate failure before the design life is reached. The maximum value is 22470 and the minimum value is 1000 cycle.

- For the static structural analysis the total deformation of connecting rod for ZL109 an aluminium alloy has been obserbed its maximum and minimum values are $0.30413 \mathrm{~mm} \& 0 \mathrm{~mm}$. maximum and minimum valuesof directional deformations are $0.08036 \mathrm{~mm} \&$ - 
$0.080367 \mathrm{~mm}$ in Z- direction. The Von-mises stress of connecting rod for ZL109 an aluminium alloy has been obserbed its maximum and minimum values are 414.02 Mpa \& 0.01734Mpa and the maximum and minimum values of maximum principal stresses are 268.71 MPa \& -39.513 MPa, The Fatigue Stress Life of the connecting rod is based on S-N curves is $10 \mathrm{e} 6$ the maximum value of biaxiality is 0.99702 which is less than one that indicates pure biaxial state. Fatigue Sensitivity Chart Shows how the fatigue results change with loading at the critical location on the components which shows the sensitivity for life of component the maximum available life 22482 cycles with respect to 1.5 loading history. For Fatigue Damage values greater than $1 \mathrm{e} 6$ indicate failure before the design life is reached. The maximum value is $1 \mathrm{e} 32$ cycle and the minimum value is 1000 cycle.

- For the dynamic structural analysis total deformation of connecting rod for ZL109 an Aluminium alloy has been observed it's maximum and minimum values are $0.30542 \mathrm{~mm} \& 0 \mathrm{~mm}$. the maximum and minimum values of directional deformation are $0.011393 \mathrm{~mm} \&$ $-0.011418 \mathrm{~mm}$. The maximum and minimum values for equivalent stress or von-mises stress of connecting rod for ZL109 aluminium alloy are 414.23 Mpa \& $0.017343 \mathrm{Mpa}$. And for maximum principal stresses its maximum and minimum values are $270.77 \mathrm{MPa} \&$ -39.609 MPa. The Fatigue Stress Life of the connecting rod is based on S-N curves is $10 \mathrm{e} 6$ the maximum value of biaxiality is 0.99702 which is less than one that indicates pure biaxial state. Fatigue Sensitivity Chart Shows how the fatigue results change with loading at the critical location on the components which shows the sensitivity for life of component the maximum available life 22325 cycles with respect to 1.5 loading history. For Fatigue Damage values greater than 1e6 indicate failure before the design life is reached. The maximum value is $1 \mathrm{e} 32$ cycle and the minimum value is 1000 cycle.

- The maximum value of factor of safety is 15 for both materials and its other values vary with increasing of load.

- The results of buckling analysis for conventional materials are 5.6095 for mode-1, 24.079 for mode-2, 47.007 for mode-3, 85.005 for mode-4, 113.65 for moad-5 and 179.77 for mode- 6 .

- The results of buckling analysis for ZL109 an Aluminium alloy are 1.9927 for mode-1, 8.5511 for mode-2, 16.689 for mode-3, 30.222 for mode-4, 40.316 for moad -5 and 63.72 for mode- 6 .

- The weight savings of the ZL109 an Aluminium alloy is equal to $25.39 \%$.

From the above statements ZL109 is best suited for replacement of connecting rod because the deformation and stressed value for both materials are almost same in both cases (static and dynamic analysis) and factor of safety of materials are also almost same but the fatigue strength of ZL109 is approximate three times than conventional material.

From the Finite elements analysis for both conventional material and proposed new material as ZL109 an Aluminium alloy it is recommended that the conventional material of connecting rod can be replaced with new proposed material which is ZL109 Aluminium alloy for better material strength and less bulky as compared to conventional material.

\section{REFERENCES:}

[1]. S Pal, S kumar and T Saboo "Design Evaluation and Optimization of Connecting Rod Parameters Using FEM", International Journal of Engineering and Management Research, Vol.-2, Issue- 2012 ISSN No.: 2250-0758

[2]. G. Naga and M Rao, "Design Optimization and Analysis of a Connecting Rod using ANSYS", International Journal of Science and Research (IJSR), Volume 2 Issue 2013 ISSN NO: 2319- 7064

[3]. K. Sudershn Kumar, Dr. K. Tirupathi Reddy and S Altaf Hussain " Modelling and Analysis of Two Wheeler Connecting Rod " International Journal of Modern Engineering Research (IJMER) www.ijmer.com Vol.2, Issue.. 2012 pp-3367-3371

[4]. B. Anusha, C.Vijaya Bhaskar Reddy, "Modelling and Analysis of Two Wheeler Connecting Rod by Using ANSYS", IOSR Journal of Mechanical and Civil Engineering (IOSR-JMCE) Volume 6, Issue 2013, PP 8387 www.iosrjournals. e-ISSN: 2278-1684,p-ISSN: 2320$334 \mathrm{X}$,

[5]. B. Anusha, Dr. C.Vijaya Bhaskar Reddy, "Comparison of Materials for Two-Wheeler Connecting Rod Using ANSYS". International Journal of Engineering Trends and Technology (IJETT) - Volume 4 Issue 9- Sep 2013

[6]. Mr. H. B. Ramani, Mr. N Kumar, Mr. P. M. Kasundra, "Analysis of Connecting Rod under Different Loading Condition Using ANSYS Software", International Journal of Engineering Research \& Technology (IJERT) Vol. 1 Issue 2012 ISSN: 2278-0181

[7]. P S Shenoy and Ali Fatemi "Connecting Rod Optimization for weight and cost reduction" SAE International journals (2005)

[8]. Y. Kumari, Dr. B V R Gupta, “ Dynamic Analysis \& Optimization of Connecting Rod Using Fem," IJRMET Vol. 3, Issue 1, Nov - Apri 1 2013, ISSN : 2249-5762 (Online) | ISSN : 2249-5770

[9]. A Gautam, K Priya Ajit, "Static Stress Analysis Of Connecting Rod Using Finite Element Approach" IOSR Journal of Mechanical and Civil Engineering (IOSR-JMCE) e-ISSN: 2278-1684,p-ISSN: 2320-334X, Volume 10, Issue . 2013, PP 47-51.

[10]. R Bansal "Dynamic Simulation Of A Connecting Rod Made Of Aluminium Alloy Using Finite Element Analysis Approach" IOSR Journal of Mechanical and Civil Engineering (IOSR-JMCE) e-ISSN: 2278-1684 Volume 5, Issue . 2013, PP 01-05.

[11].K B, Arun L.R, Mohammed Faheem "Analysis And Optimization Of Connecting Rod Using Alfasic Composites", International Journal of Innovative Research 
in Science, Engineering and Technology Vol. 2, Issue 2013 ISSN: 2319-8753.

[12].P S. Shenoy and A Fatemi "Connecting Rod Optimization For Weight And Cost Reduction"SAE Technical Paper 2005-01-0987, 2005, doi:10.4271/2005-01-0987.

[13].GVSS Sharma and P SrinivasaRao "Process Capability Improvement Of An Engine Connecting Rod Machining Process"Journal of Industrial Engineering International 2013, doi:10.1186/2251-712X-9-37.

[14].K. Sudershn Kumar, Dr.K. Tirupathi Reddy, Syed AltafHussain "Modeling And Analysis Of Two Wheeler Connecting Rod" International Journal of Modern Engineering Research (IJMER), Vol.2, Issue, 2012 pp-33673371 ISSN: 2249-6645.

[15].S Pal, S kumar "Design Evaluation and Optimization of Connecting Rod Parameters Using FEM", International Journal of Engineering and Management Research, Vol.-2, Issue-6, 2012.

[16].Prof. V C. Pathade, Dr. Dilip S. Ingole"Stress Analysis Of I.C.Engine Connecting Rod By Fem And Photoelasticity"IOSR Journal of Mechanical and Civil Engieering (IOSR-JMCE) Volume 6, Issue 12013, PP 11712 e-ISSN: 2278-1684.

[17].Priyank D. Toliya, Ravi C. Trivedi, Prof. Nikhil J. Chotai "Design And Finite Element Analysis Of Aluminium-6351 Connecting Rod"'Volume/Issue: Vol.2 - Issue 5 2013, eISSN: 2278-0181.

[18].S. Shaari, M.M. Rahman, M.M. Noor, K. Kadirgama and A.K. Amirruddin "Design Of Connecting Rod Of Internal Combustion Engine:Atopology Optimization Approachm" National Conference in Mechanical Engineering Research and Postgraduate Studies, 2010, pp.155-166.

[19]. K. M BHUTANI"Structural Analysis Of Bush Bearing For Small End Connecting Rod Using "Promechanica" NO 2012 VOLUME - 02. 2344-02 ISSN 0975 - 668X|

[20]. A Francisco, T Lavie, A Fatu and B Villechaise, J. Tribol "Metamodel-Assisted Optimization Of Connecting Rod BigEnd BearingS"135(4), 0417042013 (10 pages), Paper No: TRIB-12-1214; doi: 10.1115/1.4024555

[21]. Shahrukh Shamim,Design and Comparative Analysis of Connecting Rod using Finite Element Method,IJERT, Vol. 3 Issue 9, September- 2014

[22].G. Naga Malleshwara Rao ,Design Optimisation and Analysis of a Connecting Rod using ANSYS, IJSR,Vol.2,Issue 7,July 2013

[23].T.Chandra Sekhar,CH Joseph Sundar,MP Manmohanan,Fatigue Analysis and Life Predictions of Forged steel and Powder Metal Connecting Rods,IJERT, Vol. 3 - Issue 12 (December - 2014)

[24]. Tony George Thomas, S. Srikari, M. L. J Suman, "Design of connecting rod for heavy duty applications produced by different processes for enhanced fatigue life", SASTECH Journal, Vol. no. 10, Issue no. 1, Page no. 1-7, 2011.

[25]. Anil kumar, Kamaldeep Grover, BalvinderBudania, "Optimization of Connecting Rod Parameters using CAE Tools", International Journal of Latest Trends in Engineering and Technology, Vol. no. 1, Issue no. 3, Page no. $98-104,2012$

[26]. Mohammad Ranjbarkohan, Mohammad Reza Asadi, MasoudMohammadi, AhangariHeidar, "Fatigue Analysis of Connecting Rod of Samand Engine by Finite Element Method", Australian Journal of Basic and Applied Sciences, Vol. no. 5, Issue no. 11, Page no. 841-845, 2011.

[27]. Mansour Rasekh, Mohammad Reza Asadi, Ali Jafari, Kamran Kheiralipour, "Obtaining Maximum Stresses in Different Parts of Tractor (Mf-285) Connecting Rods Using Finite Element Method", Australian Journal of Basic and Applied Sciences, Vol. no. 3, Issue no. 2, Page no. 14381449, 2009.

[28]. Ram Bansal, "Dynamic Simulation of a Connecting Rod made of Aluminum Alloy using Finite Element Analysis Approach", IOSR Journal of Mechanical and Civil Engineering, Vol. no. 5, Issue no. 2,. Page no. 01-05, 2013.

[29].A. Mirehei, M. HedayatiZadeh, A. Jafari, M. Omid , "Fatigue analysis of connecting rod of universal tractor through finite element method (ANSYS)", Journal of Agricultural Technology, Vol. no. 4, Issue no. 2, Page no. 21-27, 2008.

[30].G.M Sayeed Ahmed, SirajuddinElyasKhany , Syed HamzaShareef "Design, Fabrication And Analysis Of A Connecting Rod With Aluminum Alloys And Carbon Fiber'International Journal of Innovative Research in Science, Engineering and Technology, ISSN: 2319-8753, Vol. 3, Issue 10, October 2014.

[31].Nikhil U.Thakare, Nitin D. Bhusale, Rahul P.Shinde, Mahesh M.Patil "Finite Element Analysis Of Connecting Rod Using Ansys" Proceedings of Third IRF International Conference on 8th February 2015, Cochin, India, ISBN: 978-93-84209-88-9.

[32].Prof. N.P.Doshi, Prof .N.K.Ingole “Analysis Of Connecting Rod Using Analytical And Finite Element Method" International Journal Of Modern Engineering Research" (IJMER) www.ijmer.com Vol.3, Issue.1, Jan-Feb. 2013, ISSN: 2249-6645.

[33]. Kuldeep B, Arun L.R, Mohammed Faheem "Analysis And Optimization Of Connecting Rod Using Alfasic Composites", ISSN: 2319-875, International Journal of Innovative Research in Science, Engineering and Technology, Vol. 2, Issue 6, June 2013.

[34].https://royalenfield.com/motorcycles/bullet-350

[35].https://www.astm.org/Standards/steel-standards.html

[36].www.chinauly.com/en/info/tech\%20info/123.html 